\title{
A Proposal for Test Data Standardization for Handsets Evaluation in Simulated Networks
}

\author{
Clauirton Siebra, Paulo Costa, Fabio Q. Silva and André M. Santos
}

\begin{abstract}
More thorough testing prior to deployment and a reduced time to market are competing objectives that handset manufacturers must try to optimize. Thus, the evolution of test methodologies, with the use of simulation environments, is an essential requirement to accelerate the product realization process. One important issue for test simulation environments is to specify the test data that is going to be used during the simulation. Such data can be classified into two groups: the test case batteries and the set of cells parameters that compose a scenario. Currently, however, we have neither a standard for a test suite that covers all the required tests for handsets certification, nor a default benchmark of real world test scenarios. This paper presents our approach to deal with both issues. First we discuss our proposal to classify and specify tests cases so that we could generate a proper test suite for handsets network tests. Then, we present our experience in creating a database with real information about handsets network scenarios of several Brazilian sites.
\end{abstract}

Keywords-Network simulation, cells description, test cases, handsets technology.

Resumo-A realização de testes em celulares e a necessidade de um rápido lançamento de tais celulares no mercado são objetivos conflitantes que os fabricantes devem otimizar. Consequentemente, a evolução das metodologias de testes, com o uso de ambientes de simulação, é um requerimento essencial para acelerar o processo de produção. Um importante aspecto dos ambientes de simulação é a especificação dos dados de testes que vão ser usados durante a simulação. Tais dados podem ser classificados em dois grupos: as baterias de casos de testes e o conjunto de parâmetros das células que compõem um cenário. Atualmente, contudo, não existe um padrão para um conjunto de testes que cubra todos os testes requeridos para a homologação de um aparelho, nem uma biblioteca padrão de testes composta por cenários do mundo real. Este artigo apresenta nossa proposta para lidar com tais aspectos. Primeiro nós discutimos nossa proposta para classificar e especificar casos de testes de forma que possamos gerar um apropriado conjunto de testes para celulares. Então, nós apresentamos nossa experiência em criar um banco de dados com informação real sobre cenários de redes para celulares em diversas regiões brasileiras.

Palavras-Chave-Simulação de redes, Descrição de células, Casos de testes, Tecnologia móvel.

\section{INTRODUCTION}

The handset development has evolved into a complex engineering process, mainly because of the current capabilities

Clauirton Siebra, Paulo Costa, Fabio Q. Silva and André M. Santos, CIn/SIDI-Samsung Laboratory of Research and Development, Federal University of Pernambuco, Recife, Brasil, E-mails: \{cas,phrc,fabio,ams\}@cin.ufpe.br. The results presented in this paper have been developed as part of a collaborative project between Samsung Institute for Development of Informatics (Samsung/SIDI) and the Centre of Informatics at the Federal University of Pernambuco (CIn/UFPE), financed by Samsung Eletronica da Amazonia Ltda., under the auspices of the Brazilian Federal Law of Informatics no. 8248/91. supported by new mobile communication and computing devices that offer a broad variety of resource and applications to users. This has increased the pressure on the test stage of the process, which is required to apply more extensive and efficient procedures of evaluation so that the final product meets the fast time-to-market goals and it can compete in the global marketplace.

Considering this fact, the use of network simulators [1] in laboratory, using a generated wireless network of low power, is a trend in replacing the manual performance of tests, which use real carriers' networks (Field-testing). However, the appropriate use of a simulation environment requires the specification of a test suite that is in fact able to testify the correctness of a handset in several situations and scenarios. For that end, the suite must consider the features of completeness (it must cover all the tests required for different carriers and test proceedings) and generality (it could be used to test any handset). Note that different carriers (each carrier provides a different wireless network) usually require different test batteries, which evaluate subsets of network operations. Furthermore, it is important that tests in laboratory can simulate real world scenarios. This means the simulated cells must be configured according to information of real handsets networks.

The remainder of this paper discusses our approaches for dealing with these issues and it is organized as follows: Section II introduces the handsets network test domain and presents an environment for networks simulation, which enables the performance of network tests in laboratory. Section III discusses the specification and classification of test cases for handsets operating in such simulated networks. Section IV describes the process of specifying test cases via a common template. Section $\mathrm{V}$ presents our experience in creating a database with real world information about handsets network scenarios. Finally, Section VI concludes this work, highlighting its main contributions and future directions of our research.

\section{Network Simulation}

Network tests for handsets intend to verity if new devices are able to perform a set of operations pre-defined by carriers. The majority of such operations, such as handovers and reselection of cells, are default operations of any carrier network. However, specific operations can be offered for just one carrier. Note that this kind of evaluation do not test the user experience features of the device, user interface, performance of data applications, battery life and others. Rather, network tests are mainly aimed at conformance (protocol performance, application enabler and radio components) and interoperability testing. 
It is known that field-testing can be costly mainly in terms of travel, time and potential disruption to the network. Such problems have motivated the development of simulation environments to wireless networks, which support the performance of a significant variety of network tests. This work, in particular, is based on our experience with the Anite/SAS network simulator [1].

The simulation environment enables the handset to communicate within any network configuration, of up to eight base stations, under laboratory conditions. A PC controller runs the network simulation software and controls the base station simulators (Cells 1 and 2). The test sets interact with the handset under test via a normal RF interface (Fig. 1) and to test end-to-end communication, the PC can be connected to Internet, allowing data to be transmitted to the handset. Using this configuration, for example, we can emulate a two cells scenario and perform tests that involve handovers, cell selection and cell reselection for circuit switched, packet based and dual transfer mode (DTM) services over GSM.

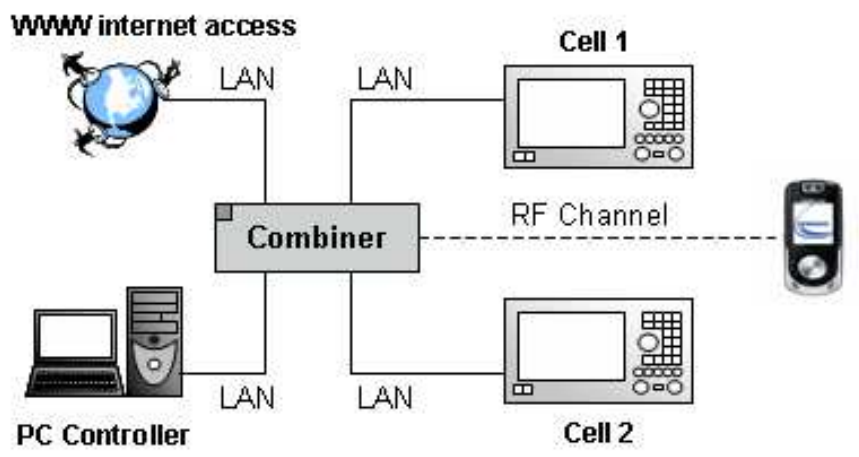

Fig. 1. Framework architecture.

An important feature of network simulation environments is their flexibility in configuring cells. At the moment we are specifying both artificial scenarios via the simulator cells editor and real scenarios via the collection and definition of a database contained real network information of several Brazilian cities. Using the editor, for example, we can set the cell identity, the channel descriptions and the frequency list. The set of all these parameters defines a cell and the collection of all cells defines a scenario. Using this architecture we have performed about $59 \%$ of the total number of tests that we have mapped.

\section{A ClassificAtion for Network Tests}

The principal sources of information, to create a suite of tests, are the requirements of carriers. Indeed, if the carriers account for creating and maintaining wireless network services, it is natural that such carriers also provide the requirements that a handset must implement to operate over their networks. However the tests provided by different carriers are not uniform and present several variations related to their procedures. Thus, we needed to carry out a process of information extraction and consolidation to create a proposal of a suite test.
There are some efforts in the direction of unifying the performance of network tests via the creation of certifications centers. These efforts vary with different technologies and geographies. For example, the procedure for evaluating the GSM technology is managed by the PCS Type Certification Review Board in the U.S., while the Global Certification Forum acts in other countries. Furthermore, groups like that also elaborate documents, such as the 3GPPTS 51.010-1, which contains collections of test cases to handsets validation. We have used documents like that to support and aggregate content to our test suite. Note that this process of generating test cases is always in evolution. For example, the third generation mobile system [4], which is based on the evolved GSM (Global System for Mobile Communications) [3] core networks, will require several new tests mainly associated with multimedia transfer communication.

Then, after consolidating all the information from carriers and certification documents, we have elaborated a classification that currently has 25 test batteries. The test cases were mainly classified according to technological aspects and kind of services that they are supposed to evaluate. Details about the batteries (battery characterization, percentage ${ }^{1}$ of tests and examples) are given in follow.

\section{A. Dual Tone Multi-Frequency (DF)}

Dual Tone Multi-Frequency, better known as touch-tone, is a system of signal tones used in telecommunications. There are twelve DF signals, each of which is made up of two tones from the following selection: $697 \mathrm{~Hz}, 770 \mathrm{~Hz}, 852 \mathrm{~Hz}, 941 \mathrm{~Hz}$, $1209 \mathrm{~Hz}, 1336 \mathrm{~Hz}, 1477 \mathrm{~Hz}$. The tones are divided into two groups (low and high) and each DF signal uses one from each group. This prevents any harmonics from being misinterpreted as part of the signal. The DF test battery represents $1.9 \%$ of the test cases and it verifies if DF signals are recognized by the network. In this way, an example of DF test is: Send DTMF command 1 .

\section{B. Emergency Call (EC)}

Many countries' public telephone networks have a single emergency telephone number, sometimes known as the universal emergency telephone number or occasionally the emergency service number, which allows a caller to contact local emergency services for assistance. The emergency telephone number may differ from country to country. It is typically a three-digit number so that it can be easily remembered and dialed quickly. The DF test battery represents $0.3 \%$ of the test cases and it verifies the network recognition of emergency calls in different situations. An example of EC test is: Make an emergency call without SIMCARD.

\section{International Mobile Equipment Identifier (IE)}

The International Mobile Equipment Identifier is a unique 15-digit number used by the GSM network to identify valid devices. Such identifier appears on the label located on the

\footnotetext{
${ }^{1}$ Amount of test case in each battery is not definitive, as well as the amount of batteries itself.
} 
back of the phone and it is automatically transmitted by the phone when the network asks for it. The IE test battery represents $0.2 \%$ of the test cases, which verify if the handset has a valid identifier. An example of IE test case is: Show the IMEI in the handset's display.

\section{International Mobile Subscriber Identifier (IS)}

An International Mobile Subscriber Identity is a unique number that is associated with all GSM and Universal Mobile Telecommunications System (UMTS) network mobile phone users. It is sent by the mobile phone to the network and is also used to acquire other details of the mobile in the Home Location Register (HLR) or as locally copied in the Visitor Location Register [3]. The IS test battery represents $0.3 \%$ of the test cases and it verifies the valid of IMSI operations over the network. An example of IS test case is: Exhibition of IMSI detach logs at BTS/Simulator.

\section{E. Phonebook Access (PA)}

The phonebook evaluation of handsets does not involve operations over the network, so that it is not required by the network standards testing. However, consumers and carriers often motivate the handsets manufactures to develop this kind of test, so that a PA battery was included in our test suite. In this way, the PA battery represents $2.4 \%$ of the test cases and it accounts for evaluating the operations that interact to the handset phonebook. An example of PA test case is: Delete a contact in SIMCARD's phonebook through the handset's menu.

\section{F. Air Signaling Tests $(R F)$}

Air Signaling or Radio Frequency tests are related to low level network operations, such as cells' selection, re-selection, handovers and broadcast. The RF battery represents $3.8 \%$ of the test cases and an example of such tests is: Re-selection between two $900 \mathrm{MHz}$ cells from the same service provider, simulating smooth power variation.

\section{G. Call Identification (CI)}

Call identification is a switching system feature that allows an attendant to visually identify the type of service or trunk group associated with a call directed to the attendant's position. The CI battery represents $2.4 \%$ of the test cases, which deal with operations related to this kind of identification. An example of CI test is: Receive a voice call from an originator listed at the SIMCard's phonebook.

\section{H. Voice Call (VC)}

Voice call is the most common operation performed over the network and there are several situations that must be evaluated, such as calls during handovers and using adaptive Multi-Rate Codec (AMR) in full and half rate. The VC category represents $5.2 \%$ of the test cases and an example is: Make a voice call to a destination that does not have neither call waiting nor voice mail.

\section{Supplementary Services (SS)}

GSM supports a comprehensive set of supplementary services that complement and support the main phone and data services. They are all defined in GSM standards and some examples are Call Forwarding and Explicit Call Transfer. The SS battery represents $4.6 \%$ of the test cases, which evaluate such services. An example of SS test case is: Disable voice calls no reply forwarding by handset's menu.

\section{J. International Calls (IC)}

Normally, before performing an international call from anywhere, we need to know the appropriate International Direct Dial code (IDD) for the country that we are calling from. With GSM however, this is not necessary because most GSM phones have a special "+ key" feature that will automatically insert the correct IDD code appropriate to your current location. The IC battery represents $0.6 \%$ of the test cases and one of their functions is to verify this "+ key" feature. An example of IC test case is: Make an international outgoing voice call.

\section{K. Unstructured Supplementary Service Data (US)}

Unstructured Supplementary Service Data is a GSM communication technology that is used to send text between a mobile phone and an application program in the network. Applications may include prepaid roaming or mobile chatting. The US battery represents $0.2 \%$ of the test case and an example of such test is: Verify if the USSD string is NOT in the dialed calls register.

\section{Short Message (SM)}

Short Message Service is a telecommunication protocol that allows the sending of "short" (160 characters or less) text messages. Such messages do not require the handset to be active and within range and will be held for a number of days until the phone is active and within range. The SM battery represents $7.4 \%$ of the test cases and it evaluates the SM service in several extreme situations, such as full SIM card and handset memory. An example of SM test case is: Send a SMS with a 160 characters text, using only letters and numbers.

\section{Enhanced Messaging Service (EM)}

Enhanced Messaging Service is an adaptation of the SM Service that allows users to send and receive ring tones and combinations of simple media. In this way, users can integrate text, melodies, pictures, sounds, and animations to enhance the expressive power of messages that are limited by the display constraints of mobile devices. The EM battery represents $4.0 \%$ of the test cases and it evaluates the traffic of this media over the network, as well as the correctness of its delivery to receivers. An example of EM test case is: Send a EMS and fill the text with no more than 160 characters, including a picture. Check if it is correctly received by its destination. 


\section{N. Multimedia Messaging Service (MM)}

Multimedia Messaging Service is a communication technology developed by $3 \mathrm{GPP}$ that allows users to exchange multimedia communications between handsets and other devices. This service is an extension and improvement of the EM service, which supports, for example, transmission of streaming video. Furthermore, unlike SM and EM services, the size of an MMS message is unlimited, although service providers are likely to impose their own size restrictions. To fully operate, the MM service requires a $3 \mathrm{G}$ network. Temporarily, however, this service has been based on the General Packet Radio Services (GPRS), which implies some limitations (a good discussion about this evolution is presented in [5]). The MM battery represents $13.9 \%$ of the test cases and we are considering the GPRS-based operations, while the $3 \mathrm{G}-$ based battery [2]) is part of our future extensions (they are already mapped but not implemented). An example of MM test case is: Receive a MMS with subject. Fill the image object with images of different sizes and formats (GIF, Animated GIF, $P N G$ and WBMP).

\section{O. Wireless Application Protocol (WP)}

The Wireless Application Protocol, or WAP, is an open international standard for applications that use wireless communication. Its principal application is to enable access to Internet from a handset. The aim of the WP battery, which represents $5.5 \%$ of the test cases, is to evaluate the use of this protocol by the handset, such as connection to WAP sessions and use of PDP (Packet Data Protocol) context. An example of WP test case is: Make a GPRS Detachment by handset's menu, without having activated a PDP context.

\section{P. Browser $(B W)$}

A handset browser provides all of the basic services of a computer based web browser, but simplified to operate within the restrictions of a handset. In this way, the BW battery represents $8.2 \%$ of the test cases and it accounts for evaluating such services. An example of BW test case is: Go to a WML $U R L$, test and check correct visualization and execution of buttons and inputs elements.

\section{Q. AT Commands (AT)}

Most GSM/UMTS handsets include an internal modem, which recognizes AT commands. Thus several operations, defined in the 3GPP TS 27.007 specification [6], can be performed using such commands. For example, standard phonebook access or short messages (SMS) sending, modification and deletion. The AT battery, which represents $4.4 \%$ of the test cases, considers these operations and an example is: Initiate a voice call using ATD command.

\section{R. $\operatorname{Java}(J V)$}

During the last years, Java is increasing its role as handset platform. One of the reasons is the popularization of J2ME (Java 2 Micro Edition) as development language for handsets.
This justifies the specification of a JV battery, whose tests cases evaluate the ability of handsets to download and execute Java applets. At the moment the JV battery represents $0.2 \%$ of the test cases and an example of such tests is: Make a Java Application download and test it.

\section{S. SIM_Card (SC)}

A Subscriber Identity Module (SIM) is a removable smart card that stores network state information which is broadcast to it from the network, such as the Location Area Identity (LAI). Another SIM function is to store a key identifying the handset service subscriber. The use of SIM cards is mandatory in the GSM world, so that their evaluation is part of the network test requirements. In this way, the SC battery represents $2.0 \%$ of the test cases and it basically verifies the SIM card capabilities. An example of SC test case is: Test the network lock by service provides.

\section{T. Bluetooth (BT)}

Bluetooth is a radio standard and communications protocol primarily designed for low power consumption, with a short range (1 meter, 10 meters or 100 meters) based on low-cost transceiver microchips in each device. Bluetooth lets these devices communicate with each other when they are in range. The devices use a radio communications system and they do not have to be in line of sight of each other. The BT battery represents $7.1 \%$ of the test cases and an example of test is: Verify that the handset discovers any devices situated nearby.

\section{U. Functionalities-Test (FT)}

The FT battery considers several test cases that are not related to network validations, however they are provided as a form to complete the handset validation. This battery represents $1.4 \%$ of the test cases and an example is: Create a welcome message and verify if it appears correctly when turn on the handset.

\section{E-mail (EL)}

The ability of sending and receiving e-mails is becoming a very common feature of handsets. In the same way that e-mails are provided by normal computer desktops, e-mails from/to handsets must consider a set of requirements, such as text format and the capability to annex several types of file format, such as figures and music files. The EL battery, which represents $8.0 \%$ of the test cases, intends to evaluate all these functions related to e-mail service for handsets. An example of EL test is: Send an email without subject, with text, and with attached sound files in different formats.

\section{W. Streaming $(S T)$}

Streaming is the kind of multimedia that is constantly received by, and normally displayed to, the end-user while it is being delivered by the provider. The name refers to the delivery method of the medium rather than to the medium itself. The ST battery, which represents $8.4 \%$ of the test cases, 
evaluates the ability of the handset in receiving this kind of media. An example of ST test is: Establish a streaming session with a server providing live content composed of video and audio where the audio is encoded using $A M R-N B$ and the video using H.264/ MPEG4-AVC.

\section{UAProf (UA)}

The User Agent Profile (UAProf) specification is concerned with capturing capability and preference information for wireless devices. This information can be used by content providers to produce content in an appropriate format for the specific device. The evaluation of related UAProf features is carried out by the UA battery, whose tests account for $4.7 \%$ of the total number of tests. An example of test is: User-Agent launched by MMS clients and URL of the UAProf.

\section{Y. Roaming Broker (RB)}

The Roaming Broker platform enables a GSM carrier to act as a hub for roaming traffic by policing signaling traffic in a centralized location. It operates as an enhanced gateway with filtering rules tailored for roaming, which enables carriers to act as brokers between roaming partners. It also has additional interoperability and security mechanisms to simplify provisioning, maximize inter-working and ensure network integrity. All these features are considered by the RB battery, which represents $2.6 \%$ of the test cases, and an example of test is: Location Update Reject - PLMN Not Allowed at two 1900 $\mathrm{MHz}$ cells with PIN1 enabled.

\section{Test Cases Specification}

The next step, after the test cases classification, is to identify and organize the common concepts related to test cases so that they can be represented in a unified way. From our analysis, we have defined the following concepts:

- Test Case Identifier: a unique key that identifies a test case (TC) among all the test cases collection. The pattern proposed in our project is < $<x_{-}$TCyyy $>$, where " $\mathrm{xx}^{\prime}$ represents the battery identifier and "yyy" represents the TC number. For example, SM_TC003 is the third test case of the Short Message (SM) battery;

- Description: a short description about the main function of a test case;

- Preconditions: required initial conditions to the performance of a test case;

- References: indicate the files, such as the test scripts, associated with a test case;

- Estimated time: average required time to perform a test case;

- A list of $\mathbf{n}$ test case steps: steps can be represented by the 4-tuple <step,technique,procedure,expected-result $>$ where step is a sequential integer value, technique specifies if the step is manual or automatic, procedure is the description of the step, and expected-result is any verification to be checked on the handset display or on the simulator execution $\log$.

Such concepts are organized in the template of Fig. 2 in order to create the test cases. Test cases can be directly used to lead the manual execution of the tests. However, considering the execution in a simulation environment, they must be translated to simulation scripts and such translation is dependent of the representation language used by each simulator.

\begin{tabular}{|c|c|c|c|}
\hline \multicolumn{2}{|c|}{ IDENTIFIER } & \multicolumn{2}{|l|}{ RF_tCO05 } \\
\hline \multicolumn{2}{|c|}{ DESCRIPTION } & \multicolumn{2}{|l|}{ Handover betwe en two $1800 \mathrm{MHz}$ cells. } \\
\hline \multicolumn{2}{|c|}{ PRECONDITION } & \multicolumn{2}{|c|}{$\begin{array}{l}\text { Handset with SIMC ard and connected to Anite Simulator } \\
\text { Both } 1800 \mathrm{MHz} \text { cells must be created in the Anite Simulator and activated. }\end{array}$} \\
\hline \multicolumn{2}{|c|}{ REFERENCES } & \multicolumn{2}{|l|}{ PI_SCP001.psc } \\
\hline \multicolumn{2}{|c|}{ ESTIMATED TIME } & \multicolumn{2}{|l|}{ 00:02:20 } \\
\hline \multicolumn{2}{|c|}{\begin{tabular}{|l|l|l} 
STEPS & TECHNIOUE \\
\end{tabular}} & PROCEDURE & EXPECTED RESULT \\
\hline 1 & Manual & Switch handset on. & 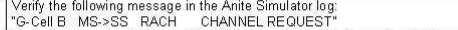 \\
\hline 2 & Automatic & Set the LOCATION UPDATE to cell B. & 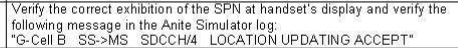 \\
\hline 4 & Manual & Make a voice call. & $\begin{array}{l}\text { Verify the following message in the Anite Simulator log: } \\
\text { G-Cell B SS-MSS SDCCHA CALL PROCEEDING" }\end{array}$ \\
\hline 5 & Automatic & Answer the voice call. & $\begin{array}{l}\text { Verify the following message in the Anite Simulator log: } \\
\text { "G-Cell B SS-MSS FACCH CALL CONNECT" }\end{array}$ \\
\hline 6 & Automatic & Execute a HANDOVER to the cell A. & $\begin{array}{l}\text { Veriff the following message in the Anite Simulator log: } \\
\text { "G-Cell A SS <-MS FACCH HANDOVER COMPLETE" }\end{array}$ \\
\hline 8 & Manual & Deactivate the voice call. & $\begin{array}{l}\text { Verify the following message in the Anite Simulator log: } \\
\text { "G-Cell A MS- }>\text { SS FACCH DISCONNECT" }\end{array}$ \\
\hline 9 & Manual & Deactivate the handset. & $\begin{array}{l}\text { Verify the following message in the Anite Simulator log: } \\
\text { "G-Cell A MS } \rightarrow \text { SS SDCCH/4 IMSI DETACH INDICATION" }\end{array}$ \\
\hline 10 & Automatic & Deactivate cell $A$ and cell $B$. & $\begin{array}{l}\text { Verfy the following message in the playback window in the Anite Simulator. } \\
\text { "Verdict. PASS" }\end{array}$ \\
\hline
\end{tabular}

Fig. 2. Example of test case specification.

\section{Databasing Real Scenarios}

Network simulators provide basic cells that we can configure to create scenarios according to specific needs. However, some carriers require the test performance in their own networks, using their cells and parameter, so that they can be sure if the handsets work properly in such networks. To still perform the tests in laboratory, we have decided to create a database with information of several real networks, so that the simulator could load this data and run simulations of real scenarios. This process is detailed in the next sections.

\section{A. Evaluation of Tools for Capture}

The first step to create a database with real network scenarios is to use a real time network monitoring tool that can capture information about cells and their parameters. Such tools are referred here as Wireless Network Capture Tools (WNCT) and we have analyzed three of them: SAGEM OT290, TEMS and NEMO.

SAGEM OT209 is a WNCT that was designed to support the validation of GSM and GPRS networks. This tool is composed by a handset-like hardware and a GSM/GPRS software that enables the visualization, recording and replay of all information. The physical interface is based on standard serial interface, which makes easier the use of the terminal in both trace and transfer modes. SAGEM is able to store measurements made in real time without the need of an external memory device. However its capability is limited, so that it is important to continually download the data to a computer using the data interface in trace mode or using an infrared connection. Apart its good usability, we have found out problems of compatibility between the SAGEM data and the Anite simulator. After loading the collected cells and configure the scenarios using such cells, we have noticed that several operations, such as Location Update, did not work properly. To attenuate this problem, we have changed some cells' parameters, turning them more "friendly" to Anite. This action had some positive effects, so that some operations, such 
as handovers between cells, were possible. However, other operations were still presenting problems and we could not apply more changes to the cells because this action could lead to cells that do not represent the real-world collected scenarios.

TEMS is an Ericsson tool that offers data collection, realtime analysis and post-processing function. One of the main aims of TEMS is to offer a multi-vendor and multi-technology support, considering the major vendors (e.g, Samsung, Motorola, Nokia, etc.) across multiple technologies (e.g, GMS, CDMA, etc.). The collected data from TEMS is presented in real time and its interface allows users to filter network data and focus on relevant information for in-depth analysis. Differently from SAGEM, the TEMS tool is composed by mobile, a PC and GSM/GPRS software that must be together during the data collection. The import of TEMS data by Anite requires the use of a specific template, which should ensure data compatibility between the two environments. Unfortunately, ever using such template, we were not able to create cells, using the collected data, in the Anite simulator.

NEMO is another option for portable engineering tool designed for measuring and monitoring the air interface of wireless networks. This tool is able to support measurements on GSM, GPRS, EDGE and WCDMA networks. Our analysis has identified that NEMO is more flexible than TEMS and SAGEM because it permits the log files export in different format, which means that the formats can be open and developers have more flexibility to work with the integration of the NEMO's data with other applications. Another positive feature is the Quadri-band capability of NEMO. This means that it is able to collect data from $850 \mathrm{MHz}, 900 \mathrm{MHz}, 1800 \mathrm{MHz}$ and $1900 \mathrm{MHz}$, depending on the handset model. However, the principal fact related to NEMO is its ongoing integration with Anite environment, which will enable a complete compatibility between these two environments.

\section{B. The Process of Capture}

The previous section raised out several features of the main tools for capture currently available in the market. In fact, the main aspect to lead the choice for a WNCT is its compatibility with the simulation environment in use. The second step to create a database of real scenarios is to define the cycles of capture. We define a cycle as a tuple <route,carrier $>$, where route defines a set of paths through where the data collection must be done; and carrier identifies one of the carriers that operates in the region.

The main idea in defining a route is to consider that this route goes through representative locations in terms of cells diversity and network traffic. Note that these locations are associated with a carrier so that the same route may not be valid for two or more carriers. Fig. 3 shows an example of route defined to capture data from four important sites of a carrier in the city center of São Paulo.

Currently we have collected information about 34 cycles, considering 12 cities and 6 different carriers. The data capture for this set of cycles must be carried out at least once a year, so that the database can actually represent the current state of real cells and scenarios.

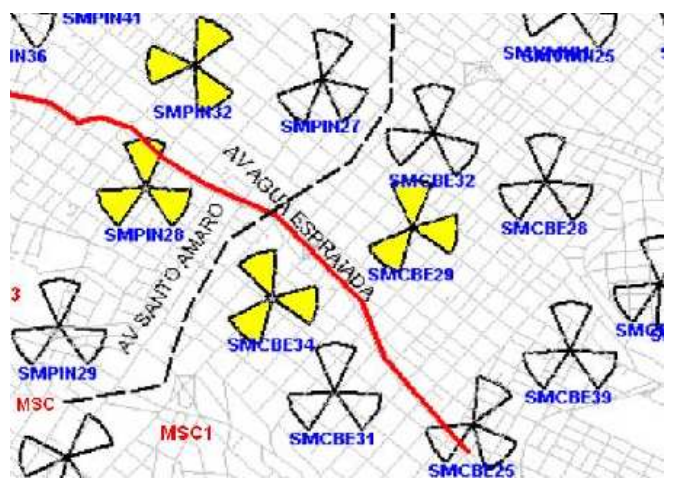

Fig. 3. Example of route, considering important sites of a specific carrier.

\section{CONCLUSIONS AND DiRECTIONS}

This paper has two main contributions. First, a proposal for classification and specification of handsets network test cases. Second, a discussion about important steps for the database creation of real wireless network scenarios. Both contributions are initial efforts towards the definition of a standard process for certification of handsets similar to those carried out by the PCS Type Certification Review Board PTCRB or Global Certification Forum GCF. In fact, there is a lack in Brazil of such kind of service, so that the task of certification is usually performed by the carriers themselves. Future efforts of this work aim to provide a complete test suite and database of network scenarios for handset certification. For that end, we need to work closer with network carriers to develop a certification program that ensures full interoperability, considering the particular features of the Brazilian networks.

\section{ACKNOWLEDGES}

The authors would like to thank all the test engineers of the CIn/SIDI-Samsung Test Center (Amanda Araujo, Anniele Costa and Ronaldo Bitu), which provided the technical details about the handsets network test domain, simulation environment and GSM principles. The team is also grateful for the support received from Samsung/SIDI team, in particular from Ariston Carvalho, Miguel Lizarraga, Ildeu Fantini and Vera Bier. The National Council for Scientific and Technological Development $(\mathrm{CNPq})$ has provided valuable support to the project through the Brazilian Federal Law no. 8010/90.

\section{REFERÊNCIAS}

[1] Anite SAS 12447D/UMOOI GSM-9OO/DCSI800/PCS-1900. Stand Alone Simulator User Manual, rel. 3.0, Anite Telecoms Ltd, Fleet, Hampshire, UK, 1999.

[2] V. Garg, Wireless Network Evolution 2G to 3G. Prentice Hall, 2001.

[3] M. Rahnema, Overview of the GSM system and protocol architecture, IEEE Communications Magazine, 42(4):493-502, 1993.

[4] The 3rd Generation Partnership Project (3GPP), Mobile Station (MS) conformance specification; Part 1: Conformance specification, 2006, Available in: http://www.3gpp.org/ftp/Specs/html-info/51-series.htm

[5] J. De Vriendt, P. Laine, C. Lerouge, and X. Xiaofeng, Mobile network evolution: a revolution on the move, IEEE Communications Magazine, 40(4):104-111, 2002.

[6] The 3rd Generation Partnership Project (3GPP), AT command set for User Equipment (UE), 2007. Available in: http://www.3gpp.org/ftp/Specs/html-info/27007.htm 